\title{
Response Surface Analysis: A Tutorial for Examining Linear and Curvilinear Effects
}

\author{
Análise de Superfície de Resposta: Um Tutorial para Examinar Efeitos \\ Lineares e Curvilíneos
}

Antonio Carlos Rodrigues*1 1

\section{ABSTRACT}

Context: response surface analysis (RSA) is an approach that allows examining the extent to which combinations of two predictive variables relate to one outcome variable. The method is particularly interesting in cases where (in)congruence between the two predictive variables is a central consideration of the study. Objective: the purpose of this article is to provide a tutorial on applying RSA. Method: the method's conceptual background and an illustrative example are provided so that the reader can understand some of the basic principles of the technique. This tutorial's target audience is researchers who use mathematical modeling but are not yet familiar with the method. Results: the technique has the potential for application in various research questions in the field of Administration. Conclusions: besides providing a tutorial on how to use the investigated technique, the study demonstrates its relevance in the analysis of congruence and incongruence between the scores.

Keywords: response surface analysis; polynomial regression; tutorial; quantitative methods.

\footnotetext{
* Corresponding Author.

1. Universidade Federal de Juiz de Fora, Instituto de Ciências Sociais Aplicadas, Departamento de Administração, Governador Valadares, MG, Brazil.
}

Cite as: Rodrigues, A. C. (2021). Response surface analysis: A tutorial for examining linear and curvilinear effects. Revista de Administração Contemporânea, 25(6), e200293. https://doi.org/10.1590/1982-7849rac2021200293.en

\section{RESUMO}

Contexto: a análise de superfície de resposta (RSA) é uma abordagem que permite examinar até que ponto combinaçóes de duas variáveis preditivas se relacionam com uma variável de resultado. O método é particularmente interessante nos casos em que a (in)congruência entre as duas variáveis preditivas é uma consideração central do estudo. Objetivo: o propósito deste artigo é apresentar um tutorial sobre aplicaçáo da RSA. Método: são fornecidos fundamentaçáo conceitual do método e um exemplo ilustrativo, para que o leitor possa entender alguns dos princípios básicos da técnica. O público-alvo deste tutorial são pesquisadores que utilizam modelagem matemática, mas que ainda não estão familiarizados com o método. Resultados: a técnica apresenta grande potencial de aplicação em uma variedade de questôes de pesquisa no campo da Administração. Conclusóes: além de fornecer um tutorial para uso da técnica, demonstrase sua relevância para os estudos que analisam congruência e incongruência entre os escores.

Palavras-chave: análise de superfície de resposta; regressão polinomial; tutorial; métodos quantitativos.
JEL Code: $\mathrm{C} 1, \mathrm{C} 4, \mathrm{~A} 2$

Editor-in-chief: Wesley Mendes-da-Silva (Fundação Getulio Vargas, EAESP, Brazil) (]) Associate Editor: Henrique Castro Martins (PUC Rio, IAG, Brazill) Reviewers: Luciano Rossoni (Universidade Federal de Uberlândia, PPGAdm, Brazil) (1) Pierre Oberson de Souza (Fundação Getulio Vargas, EAESP, Brazil) c] Peer Review Report: The Peer Review Report is available at this external URL.

$\sum_{0}^{0}$




\section{INTRODUCTION}

Response surface analysis (RSA) is a technique that can provide a nuanced view of relationships between combinations of two predictor variables and an outcome variable by graphing the results of polynomial regression analyses in a three-dimensional space (Edwards \& Parry, 1993). The approach emerged as a solution to the problems associated with the use of difference scores to analyze discrepancies (Edwards, 2002; Shanock, Baran, Gentry, Pattison, \& Heggestad, 2010). The purpose of this tutorial article is to provide a tutorial on applying RSA.

The use of RSA has many advantages over the scores of traditional differences. Initially, these approaches compute two predictor variables into a single score, which reduces the available information. For this reason, the difference scores confuse the effects of each of the component measures on the result. The difference scores do not tell us the extent to which each of the component measures contributes to the outcome variable. Thus, completely different situations may lead to similar averages. Using polynomial regressions with RSA instead allows researchers to overcome these limitations and deal with congruence hypotheses (Edwards \& Parry, 1993).

Congruence hypotheses state that the agreement (i.e., congruence) between two constructs should positively (or negatively) affect some outcome variable. Such hypotheses play a central role in many disciplines, for example, Marketing (Kim \& Hsieh, 2003), Organizational Behavior (Caniëls \& Veld, 2019), and Purchasing (Caniëls, Vos, Schiele, \& Pulles, 2018). Congruence hypotheses have traditionally been investigated by correlating difference scores with the outcome variable. This approach is, as previously argued, biased toward falsely claiming support for the hypothesis. RSA makes it possible to examine whether the degree of congruence of two variables is related to an outcome variable. Then, response surface methodology is a suitable approach applied to interpret the resulting response surface to determine whether the estimated model reflects the proposed congruence hypothesis.

Additionally, RSA differs from interaction analysis, since it too includes two nonlinear effects rather than only an interaction term in the regression equation. These nonlinear terms allow one to examine whether an apparent interaction effect is a curvilinear effect. Although several theories and issues require nonlinearity, supply chain research approaches problems linearly. In this sense, even though the real relationship between the component measures and the outcome measure is curvilinear, the linear models have oversimplified the relationship and masked the real relationships between the variables (Edwards, 2002; Shanock et al., 2010). The use of this technique is an alternative to the nonlinear assumptions test that provides a significant exploratory and explanatory potential for the phenomenon under investigation.

RSA is presented here as a robust methodological solution that provides detailed answers to crucial questions in several constructs in this area of research. In summary, in addition to overcoming traditional approaches to measuring the effects between parties, calculate the algebraic difference between dependencies, the average or the sum of these measures, or use spline scores. For this reason, RSA provides a powerful alternative approach to test congruence hypothesis. The technique can test, at the same time, hypotheses of curvilinear effect and moderation without having to interact with independent variables. Naturally, the use of nonlinear postulations in the analysis has the potential to discover the complex and contingent relationship that the theory originally suggested between the constructs. For this reason, the method is superior to the frequently used approaches because such approaches can provide incomplete or even incorrect conclusions due to their statistical limitations.

To better understand the reasons for using RSA, the rest of this tutorial is structured as follows. Initially, in the second section, a review of the basics of RSA is presented. Sequentially, the background of the example used in this tutorial is exposed in the third section. In the fourth section, we present the steps for applying RSA. Subsequently, there is a section about the advantages and limitations of RSA. Finally, in the sixth section, we present the conclusions and implications.

\section{THE BASIC OF RSA}

Imagine that a researcher is investigating whether when buyer and supplier have similar perceptions of dependence, there is a higher level of satisfaction with relationships compared to relationships with asymmetric perceptions (Caniëls et al., 2018; Kumar, Scheer, \& Steenkamp, 1995; Leonidou, Talias, \& Leonidou, 2008). It can be hypothesized, according to the literature, that asymmetric relationships, in which a partner dominates the exchange, are less useful because the dominant partner can exploit his power position (Casciaro \& Piskorski, 2005; Gulati \& Sytch, 2007; Ireland \& Webb, 2007). Therefore, a hypothesis of similarity effect could be expressed by: the greater the dependence of the buyer $(\mathrm{X})$ and the supplier $(\mathrm{Y})$, the greater the satisfaction with the relationship $(\mathrm{Z})$. Therefore, we would have to evaluate three variables: the two predictors $\mathrm{X}$ (for example, buyer perception) and $\mathrm{Y}$ (for example, supplier perception), whose comparison is of interest to us, and the result variable $\mathrm{Z}$ (for example, relationship satisfaction). 
The recurrent approach in the literature to measure the dependence between the parties would be necessary to calculate the difference and the algebraic sum between the dependencies between buyer and suppliers to carry out the analyses (Griffith, Hoppner, Lee, \& Schoenherr, 2017; Gulati \& Sytch, 2007; Kumar et al., 1995). For example, for spline scores, the difference between supplier dependence (SD) and buyer dependence (BD) is calculated. So, the supplier's dominance is equal to $\mathrm{SD}-\mathrm{BD}$, if $(\mathrm{BD}>\mathrm{SD})$ and zero otherwise. On the other hand, the buyer's domain is BD - SD if (SD > BD) and zero otherwise. Hofer (2015) used spline specification to the measure of the extent and direction of the dependence asymmetry in his study. The spline measure of a customer dependence advantage was created by subtracting customer dependence from third party logistics (3PL) dependence. All negative values were recoded to zero. The spline measure of customer disadvantage was calculated by subtracting 3PL dependence from customer dependence, recoding all negative values to zero. However, methodological disadvantages can be highlighted by using the previous approach. Two predictive variables (that is, buyer dependence and supplier dependence) are transformed into a single score (that is, relative dependence), which reduces the available information. Therefore, completely different situations can lead to similar averages. Response surface analysis, in turn, is an adequate statistical tool to investigate these similarity effects because it overcomes the difficulties of traditional methods in terms of information reduction. In addition, the method includes the possibility of capturing nonlinear effects of the predictor variables, that is, verifying whether an interaction effect is a curvilinear effect.

In the RSA approach, polynomial regression is conducted first. The basic element of RSA is the estimation of a second-order polynomial regression model that can be written in general as:

$$
Z=b_{0}+b_{1} X+b_{2} Y+b_{3} X^{2}+b_{4} X Y+b_{5} Y^{2}+e
$$

where $\mathrm{Z}$ is a dependent variable, $\mathrm{X}$ is predictor 1 , and $\mathrm{Y}$ is predictor 2. Thus, the outcome variable $Z$ is regressed against its predictors $\mathrm{X}$ and $\mathrm{Y}$, their respective square terms $\mathrm{X}^{2}$ and $\mathrm{Y}^{2}$, and their interaction $\mathrm{XY}$.

The foundation of RSA is the visualization of the results of the regression equation on a three-dimensional graph (Edwards, 2002; Schönbrodt, Humberg, \& Nestler, 2018; Shanock et al., 2010). Instead of directly interpreting the results of the polynomial regression analysis, the coefficients are used to examine what is called a 'response surface pattern' (Edwards, 2002; Shanock et al., 2010). The response surface is a graph that provides a three-dimensional visual representation of the data to aid interpretation. A response surface for a similarity effect is shown in Figure 1 as an example. The two predictor variables $\mathrm{X}$ and $\mathrm{Y}$ are located on the two axes at the bottom of the coordinate cube. For each combination of $X$ and $Y$, the respective $Z$ value predicted by the model is reflected in the vertical axis, thus indicated by the height of the surface. For example, given the coordinate $(\mathrm{X}, \mathrm{Y})$, which is represented as a circle at the bottom of the cube, the surface in Figure 1 predicts the result value $\mathrm{Z}$, which is symbolized by a star on the regression surface.

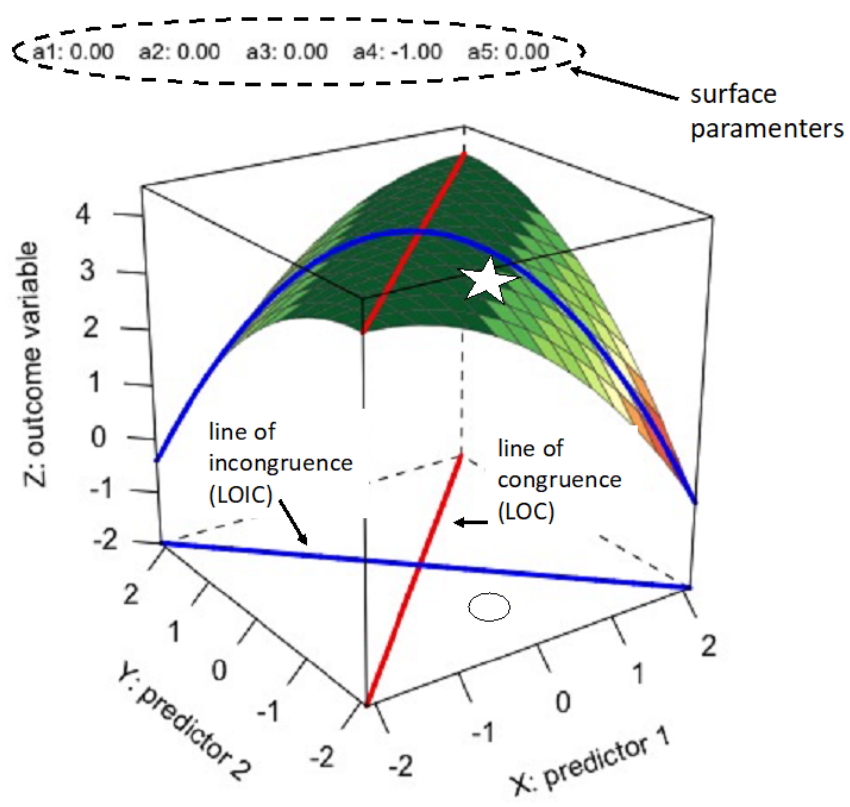

Figure 1. Response surface example.

Source: Adapted from Schönbrodt, Humberg, and Nestler (2018).

In summary, RSA provides tools for the graphical and statistical interpretation of the regression surface, for example, concerning the existence or not of similarity effects. The slope and curvature of two lines, line of congruence (LOC) and line of incongruence (LOIC), represent possible response surface patterns.

\section{Line of congruence (LOC)}

The line of congruence represents all combinations where $\mathrm{X}=\mathrm{Y}$ (see the straight red line at the bottom of Figure 1). When considered about the result variable (Z), the slope of the line of congruence represents how the level of congruence between two predictor variables affects a result variable. That is, the slope of the LOC shows the different levels of the outcome variable (for example, satisfaction) for an actor whose levels of the two predictor variables (for example, buyer dependence and supplier dependence) are necessarily the same across the continuum from minimum scores to maximum scores in both predictors. In this sense, 
the perfect congruence of two variables is not reflected in a single combination of corresponding $\mathrm{X}$ and $\mathrm{Y}$ values, but in all combinations for which $\mathrm{X}$ is equal to $\mathrm{Y}$. Therefore, the partners can be similar at a low level (for example, both are not very dependent on the partner), intermediate, or high (both are very dependent). All possible combinations of perfect congruence are located on the congruence line at the bottom of the coordinate cube (Figure 1), which diagonally connects the front (the low/low congruence combination) to the back (the high/high congruence combination) of the cube.

The surface above the LOC is represented by a red line on the surface, which reflects how the predicted result behaves for variable values of $\mathrm{X}=\mathrm{Y}$. Statistically, the surface above the LOC is described by the formula $\mathrm{Z}=\mathrm{a}_{1} \mathrm{X}+\mathrm{a}^{2} \mathrm{X}^{2}$ (without the intercept). The parameters $\mathrm{a}_{1}$ and $\mathrm{a}_{2}$ are derived from the estimated regression coefficients of equation (1), where $\mathrm{a}_{1}=\mathrm{b}_{1}+\mathrm{b}_{2}$ and $\mathrm{a}_{2}=\mathrm{b}_{3}+\mathrm{b}_{4}+\mathrm{b}_{5}$ (Shanock et al., 2010). The parameter $a_{2}$ indicates whether the LOC is linear (if $\mathrm{a}_{2}=0$ ) or curved (if $\mathrm{a}_{2} \neq 0$ ), while parameter $\mathrm{a}_{1}$ describes the slope of the LOC above the point $(0,0)$. In Figures $2 \mathrm{~A}$ and $2 \mathrm{~B}, \mathrm{a}_{2}$ is equal to zero, indicating that LOC is a straight line, while in Figure $2 \mathrm{C}_{2}$ is different from zero - LOC is a curved line. In this case, $\mathrm{a}_{1}$ is simply the slope of the line. As $\mathrm{a}_{1}=0$ in Figure 1, the predicted result value above the LOC is constant. Figure $2 \mathrm{~A}$ shows a predicted linear and non-constant result over the LOC, which describes a rising ridge surface. The result is greater when $\mathrm{X}$ is identical to $\mathrm{Y}$. In addition to this basic similarity pattern, there is an effect of the similarity level: congruent combinations at a high predictive level lead to higher result values than congruent combinations at a low predictive level. Figures 2D, 2E, and $2 \mathrm{~F}$, in contrast, represent surfaces with a curvilinear LOC. In Figure 2D, for example, the result is higher for a specific combination of buyer and supplier openings (that is, $\mathrm{X}=0$ and $\mathrm{Y}=0$ ) and is lower for all other combinations of the two predictors.
(A) Rising ridge:

$$
a_{1}>0, a_{4}<0
$$

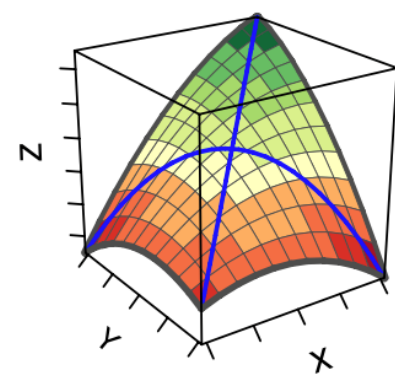

(D) Dome:

$a_{2}<0, a_{4}<0$

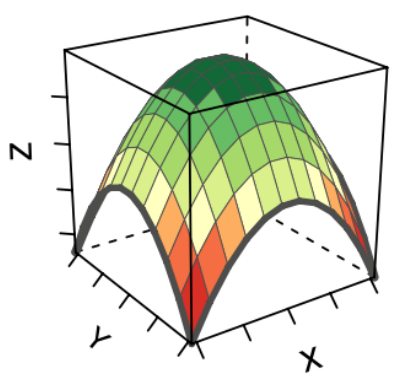

(B) Optimal margin:

$a_{4}<0, a_{3} \neq 0$

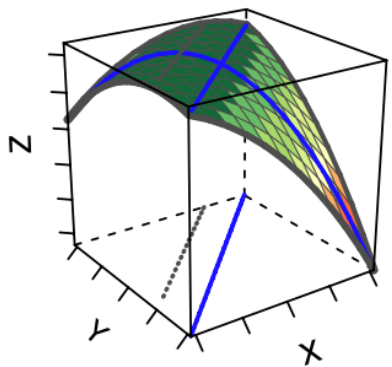

(E) Bowl:

$a_{2}>0, a_{4}>0$

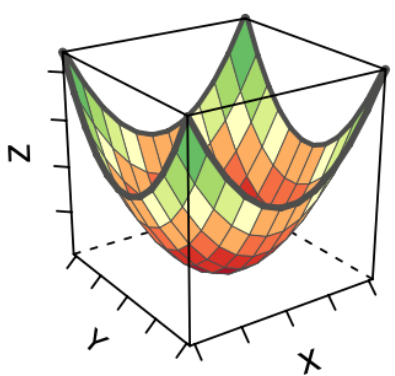

(C) Interaction:

$a_{1}=0, a_{3}=0, a_{2}>0, a_{4}<0$ (or v.v.)

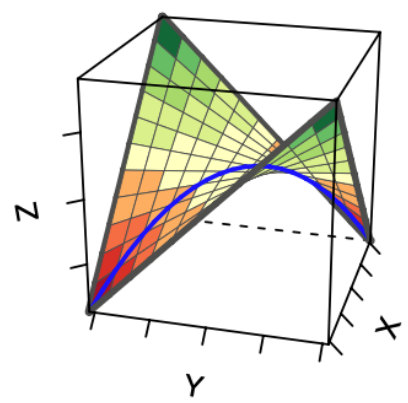

(F) Saddle:

$a_{2}>0, a_{4}<0$ (or vice versa)

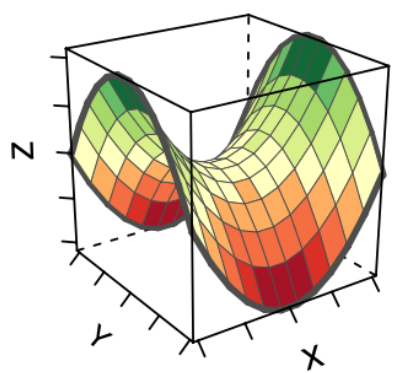

Figure 2. Multiple examples of RSA configurations.

Source: Adapted from Schönbrodt et al. (2018). 


\section{Line of incongruence (LOIC)}

The line perpendicular to the congruence line (LOC) is often called the incongruence line (LOIC). It covers all valid combinations of predictors for which $\mathrm{Y}=-\mathrm{X}$. A significant curvature along this line (related to the height of the outcome variable) captures how the degree of discrepancy between the two predictor variables can influence the outcome variable. This line is represented by the blue line at the bottom of the cube and on the surface of Figure 1, respectively, which runs from the left corner to the right corner of the cube. It goes from one incongruent extreme (low X / high Y combinations) to the other (high $\mathrm{X} /$ low $\mathrm{Y}$ combinations). LOIC is determined by the quadratic equation $Z=a_{3} X+a_{4} X^{2}$, where $a_{3}=b_{1}-b_{2}$ and $\mathrm{a}_{4}=\mathrm{b}_{3}-\mathrm{b}_{4}+\mathrm{b}_{5}$. The coefficient of the quadratic term, $\mathrm{a}_{4}$, indicates whether the LOIC on the surface is linear or curvilinear. In the case of Figure 1, $\mathrm{a}_{4}$ is negative $\left(\mathrm{a}_{4}=-1\right)$, indicating that the LOIC has an inverted U shape; therefore, it has a maximum point and curves symmetrically downward on both sides from this point. In this situation (that is, when $a_{4} \neq 0$ ), the coefficient $a_{3}$ indicates the position of the highest or lowest point of the LOIC. In Figure $1, \mathrm{a}_{3}=0$, which means that the LOIC's highest point is positioned exactly above $(0,0)$. LOIC is maximum for $\mathrm{X}=\mathrm{Y}=0$ and slopes downward for values of $\mathrm{X}$ and $\mathrm{Y}$ that deviate more and more from one another, in the direction of $\mathrm{X}>\mathrm{Y}$ (toward the right corner of the cube) or toward of $\mathrm{X}<\mathrm{Y}$ (towards the left corner). Figure 2B shows an exemplary U-shaped surface inverted in the LOIC (i.e. $\left.\mathrm{a}_{4}<0\right)$ to which the ridge is moved away from the LOC $\left(a_{3} \neq 0\right)$. Here, the result is maximum when $\mathrm{Y}$ is greater than $\mathrm{X}$ by a certain amount.

In this sense, the LOIC slope, that is, the height in the result variable, informs the researcher to what extent the direction of the discrepancy is essential, and that the result is potentially more affected when the discrepancy is in an $\mathrm{X}>\mathrm{Y}$ direction or the other $\mathrm{X}<\mathrm{Y}$.

To determine whether a response surface reflects a similarity effect, one needs to test the four conditions on $\mathrm{a}_{1}$ to $\mathrm{a}_{4}$ (i.e., $\mathrm{a}_{1}=\mathrm{a}_{2}=\mathrm{a}_{3}=0$ and $\mathrm{a}_{4}<0$ ), and in addition, one needs to find out whether the ridge line ('first principal axis,' in mathematical terms) of the surface is positioned at the LOC. The position of the ridge line can in general be determined by considering its projection onto the X-Y plane. When one understands the X-Y plane as a coordinate system in itself, one can express the position of the ridge as a linear equation that relates $\mathrm{Y}$ to $\mathrm{X}$. The much easier way to test whether the ridge equals the LOC: in this case, it suffices to test whether $a_{5}=b_{3}-b_{5}=0$ - ridge line equals the LOC; see Schönbrodt et al. (2018) for details on this condition.
The $\mathrm{R}$ package RSA provides point estimates, confidence intervals, and significance tests for all surface parameters

\section{Commensurability}

The LOC refers to the numerical congruence of the scales while the LOIC corresponds to numerical differences in one or the other direction. This numerical comparison is only possible if the two variables were measured on the same scale. When the two measures are on the same scale, they are commensurable (Edwards, 2002; Humberg, Nestler, \& Back, 2019; Shanock et al., 2010). Commensurability encompasses two aspects, namely: (a) nominal equivalence, in which both scales measure the same latent construct; and (b) scale equivalence, in which both scales have the same metric. Such aspects are generally addressed using the same measurement scales for both partners. For example, imagine that we were trying to predict the perceived performance of the buyer relationship in one through the relational capital of both parties in a buyer-supplier dyad. The conceptual domain of the predictor variables is the relational capital perceived by the buyer and the supplier. In this case, a difference between the relational capital of the buyer and the supplier and the performance perceived by the buyer, for example, could be significant because the measures come from the same conceptual domain. In addition, the predictor variables need to be measured on the same numerical scale so that their degree of correspondence can be determined (Edwards, 2002). Thus, both variables could be measured on the Likert scale with the same score. If the variables are not measured on the same scale, it is necessary to standardize the scales of the variables, placing them on a common metric (Barranti, Carlson, \& Côté, 2017; Schönbrodt et al., 2018). Finally, it should be noted that as with any regression technique, all the usual assumptions of multiple regression analysis must be met (Hair, Black, Babin, \& Anderson, 2014; Tabachnick \& Fidell, 2012). Polynomial regression can provide information on combinations of variables that go far beyond the information provided by traditional regression.

\section{BACKGROUND ABOUT THE EXAMPLE}

The example presented in this study is based on the perception of dependence on buyers and suppliers as a determinant of buyer satisfaction. The theoretical foundations of resource dependence theory and social exchange hold that organizations are interconnected systems that need resources for survival (Blau, 1964; Emerson, 1976; Pfeffer \& Salancik, 1978). The need for the resources that other actors have generates dependence and, in turn, determines the power dynamics in inter-organizational relationships. In 
a general definition, dependence is expressed by the need for a company to continue its relationship with an exchange partner to achieve its desired goals (Pfeffer \& Salancik, 1978). The consequence of relative dependence is translated as power. Thus, the power of one organization over another is the result of net dependence on one another. If $A$ depends on $\mathrm{B}$ more than $\mathrm{B}$ depends on $\mathrm{A}$, then $\mathrm{B}$ has power over $\mathrm{A}$ (Blau, 1964; Pfeffer \& Salancik, 1978). The investigation of inter-organizational dependence, therefore, requires a bilateral view, which considers both buyer dependence and supplier dependence. This structural perspective of power has been dominant in explaining the role of power in forming relationships between organizations.

In our example, we focus on power as a direct result of resource dependence. The reason for the widespread adoption of the structural perspective may be that access to resources represents one of the main incentives for organizations to engage in interactions with other organizations (Pfeffer \& Salancik, 1978). We operate the domain of power as the difference between buyer dependence (BD) and supplier dependence (SD). The solid diagonal line in Figure 3 refers to a situation where the dependence on buyers is equal to the dependence on suppliers. In asymmetric relationships, the most powerful partner dominates the exchange, and this study refers to this situation as characterized by the asymmetry of interdependence (Caniëls et al., 2018; Casciaro \& Piskorski, 2005; Gulati \& Sytch, 2007). In these types of relationships, the most independent partner experiences high power and may be tempted to exploit it (Crook, Craighead, \& Autry, 2017; Gulati \& Sytch, 2007; Ireland \& Webb, 2007). Above the solid diagonal line in Figure 3, the buyer's dependence is greater than that of the supplier, so we have an asymmetric relationship dominated by the supplier. Likewise, below the diagonal, there is a situation of dominance of the buyer.

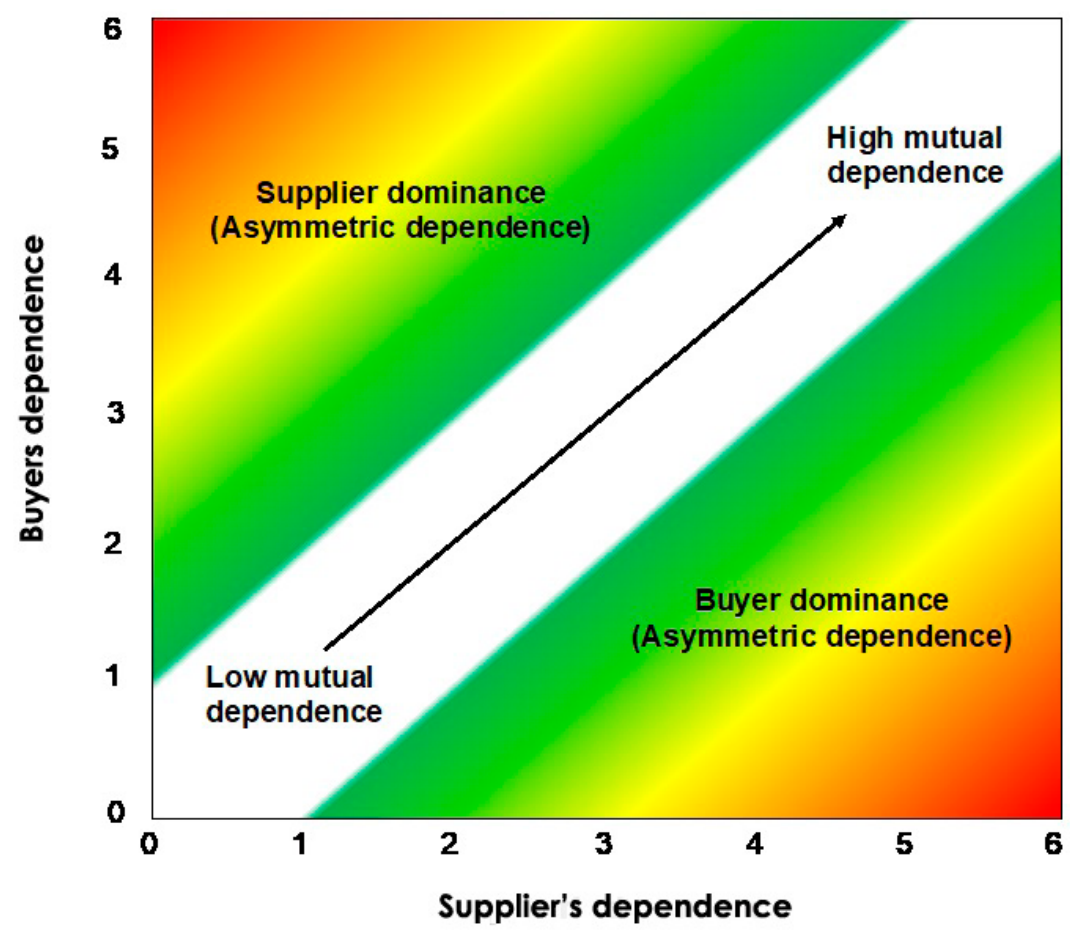

Figure 3. Buyer-supplier dependence.

Source: Adapted from Caniëls, Vos, Schiele, and Pulles (2018).

On the other hand, mutual dependence reduces transaction uncertainty, increases information sharing, and improves conflict resolution (Gaski, 1984; Kumar et al., 1995; Kumar, Scheer, \& Steenkamp, 1998). Low levels of mutual dependence may reflect buyer-supplier relationships with non-critical routine products. High levels of mutual dependence can indicate strongly cooperative relationships
(Gulati \& Sytch, 2007). Furthermore, when both parties are aware of (high) dependence on each other, it is unlikely that both sides will abuse their position. The risk of retaliation in such situations is easily perceived as very high (Caniëls et al., 2018; Casciaro \& Piskorski, 2005; Gulati \& Sytch, 2007). Therefore, the degree to which a buyer-supplier relationship is characterized by mutual dependence can be 
expected to positively influence relational behavior due to the prevention of relational risks and the value that both partners perceive in the relationship. Relationships in which buyer and supplier are mutually dependent at a high level are therefore more likely to generate high levels of buyer satisfaction.

Dependence asymmetry is generally associated with a negative influence on performance, reducing the willingness to compromise or adapt (Gulati \& Sytch, 2007; Kumar et al., 1995). In asymmetric relationships, a partner dominates the exchange (Casciaro \& Piskorski, 2005; Gulati \& Sytch, 2007). Current views dictate that these relationships are less effective because the dominant partner may be tempted to exploit his position (Caniëls et al., 2018; Ireland \& Webb, 2007). Generally, the mere presence of asymmetric positions in relationships is associated with instability and conflict (Gaski, 1984; Nyaga, Lynch, Marshall, \& Ambrose, 2013). If the continuity of the relationship is not a priority, the dominant partner can appropriate most of the created relational value (Brito \& Miguel, 2017; Caniëls et al., 2018). Purchasing companies are more likely to extract high value from supplier relationships if they maintain a dominant position (Reimann \& Ketchen, 2017; Reimann, Shen, \& Kaufmann, 2017).

For a clearer demonstration, data from Schönbrodt et al. (2018) were used. The dataset for reproducing the results and the figures can be downloaded in supplementary material of this tutorial. The unit of analysis used was the relationship, and the data included both perspectives (buyer and supplier) of each dyad. The study of the dyad allows for an effective capture of the specificities of interorganizational relationships. The dataset included matching the buyer and supplier views resulted in 300 dyads. All items were measured on 10-point Likert scales. The anchors for these scales were 1 = strongly agree to $10=$ strongly disagree. In our example, buyer dependence $(\mathrm{BD})$ is variable $\mathrm{X}$, supplier dependence (SD) is variable $\mathrm{Y}$, and buyer satisfaction relationship (SAT) is our result variable $(\mathrm{Z})$. We renamed variables to illustration an example in supply chain ${ }^{1}$.

As $\mathrm{BD}$ and $\mathrm{SD}$ are positively related to SAT, when $\mathrm{BD}$ and SD agree (that is, the parties' perceptions of their dependence are necessarily at the same level), a linear relationship is proposed in which the greater $\mathrm{BD}$ and $\mathrm{SD}$, the greater it will be SAT. Thus, a significant positive slope is expected along the line $\mathrm{X}=\mathrm{Y}$ (i.e., LOC) related to SAT. The simulated data used in this tutorial represent the mean score of items from the scales of the studies by Kumar, Scheer, and Steenkamp (1995) - buyer and supplier dependence - and Hoppner, Griffith, and Yeo (2014) - satisfaction performance. All data are available in .csv format.

We also propose that when the BD is greater than the SD or vice versa, the SAT will be less than when the two support variables are in agreement. That is, we expect the SAT levels to decrease as the discrepancy between these two support variables increases. This proposition corresponds to an expectation of a significant and negative curvature along the line of incongruence (that is, the line $\mathrm{X}=-\mathrm{Y}$ ) concerning SAT. In addition, the direction of the discrepancy can differentially influence the SAT. The SD can be more critical for the maintenance of $\mathrm{BD}$, as it represents a more significant commitment from the supplier to the relationship than from the buyer. The SD creates a felt obligation to be concerned with the well-being of the relationship due to the benefits acquired or the costs incurred by closing the exchange. Thus, we propose that when the direction of the discrepancy is such that the $\mathrm{BD}$ is greater than the $\mathrm{SD}$, the SAT level will be less than when the $\mathrm{SD}$ is less than the $\mathrm{BD}$. Therefore, we expect a significant negative slope for the $\mathrm{X}=-\mathrm{Y}$ line concerning SAT.

\section{STEPS FOR CONDUCTION RSA}

The entire process we describe below can generally be achieved in one step using the RSA package (version 0.10.0) in R (Schönbrodt \& Humberg, 2020). However, conceptually RSA is divided into two stages: (a) running a polynomial regression model and (b) using the results of the model to generate a response surface and analyze the importance of the effects (Edwards, 2002; Shanock et al., 2010). In this sense, the interpretation of the RSA results is directed to the response surface and not to the effects of polynomial regression. In RSA, data must meet the premises of multiple regression (Barranti et al., 2017; Shanock et al., 2010). Besides, the two predictors must be proportional, representing the same content domain and measured on the same interval or ratio scale (Edwards, 2002).

\section{Data preparation}

Some steps of data preparation should be done before computing the model (Schönbrodt et al., 2018).

First, the RSA framework requires data to be stored in the wide format, so that each row contains data from one dyad and each measured variable has a separate column for each dyad member. This data format clarifies that the unit of analysis is the dyad, and that degrees of freedom usually refer to the number of dyads. The dataset for this tutorial is providing in a separate file, it is possible to import the data from the .csv file by \#Step 1 and \#Step 2.

Second, the centralization procedure of both predictors at the midpoint of the scale ensures that the interpretation of the results is consistent with the theories of how the correspondences and non-correspondences of perceptions are related to the results. Therefore, predictors 
must be standardized. If the predictors are not standardized, a change from one unit in one predictor may not have the same meaning as a change from a unit in the other predictor (Edwards, 2002), excluding inferences about how (in) congruence relates to results. Researchers should exercise extreme caution if they do not centralize predictors at the midpoint of the scale because this fundamentally changes the interpretation of a correspondence - usually to something complicated, not intuitive, and inconsistent with the theory. Predictors must be centralized (BD and SD) around the midpoint of their respective scales (Shanock et al., 2010). Centering around the midpoint of the scale is recommended for this type of analysis because it is essential to centralize the predictive variables of both parties so that they have a common zero point (Edwards \& Parry, 1993; Shanock et al., 2010). This can, for example, be achieved by subtracting the midpoint of the response scale (for example, 4 on a scale of 1 to 7 , which ranges from strongly disagree [1] to strongly agree [7]) from $\mathrm{X}$ and $\mathrm{Y}$. It is appropriate when the midpoint of the scale is semantically significant. However, Schönbrodt et al. (2018) point out that centering the predictors on their grand mean is more suitable because it does not presume that the midpoint of the scale is semantically meaningful and that the distributions of the two variables are similar (e.g., the same skewness and kurtosis). We are centering the predictors in \#Step 3 by grand mean centering.

Third, missing values are a potential source for bias and distorted standard errors. For example, in the case of RSA, a single missing value in $\mathrm{Y}$ propagates further to missing values in $\mathrm{Y}^{2}$ and $\mathrm{XY}$. An in-depth treatment of missing values is beyond the scope of this paper, but it is possible to use deletion or apply methods like a maximum likelihood estimation based on all available data to treatment of missing values. Finally, regression results can be spurious if they are driven by a small number of outliers, and the squared terms of the polynomial regression even exaggerate the impact of outliers. Therefore, it recommends screening the data set for multivariate outliers. The RSA function from the RSA package can treat missing values and multivariate outliers. The \#Step 4 allows the researcher to perform the procedures described.

Four, before performing the polynomial regression analyses, it is essential to inspect how many participants would be considered discrepancies between the two predictors. The procedure allows the researcher to have an idea of the basic rate of discrepancies in the sample. If there are few participants with outliers (for example, BD greater than $\mathrm{SD}$ or $\mathrm{SD}$ greater than $\mathrm{BD}$ ), the practical value of exploring how discrepancies affect a result variable would be small. Researchers need to carry out this verification because the results are not reliable in the absence of one or the other. The RSA package automatically generates this output (that is, the percentage of observations where $\mathrm{X}$ is greater than, equal to, or less than $\mathrm{Y}$ ) based on whether the predictors are within half of a $\mathrm{Z}$ scoring unit.

Table 1. Frequencies of dependence levels of buyer and supplier dependencies.

\begin{tabular}{ccccccc}
\hline \multirow{2}{*}{ Groups } & \multirow{2}{*}{ No. } & \multirow{2}{*}{$*$} & \multicolumn{2}{c}{ Buyer dependence } & \multicolumn{2}{c}{ Supplier dependence } \\
\cline { 4 - 7 } & & & $\mathrm{M}$ & $\mathrm{SD}$ & $\mathrm{M}$ & $\mathrm{SD}$ \\
\hline Supplier dominance & 120 & $40.00 \%$ & 8.15 & 1.68 & 5.68 & 1.58 \\
Similar dominance & 37 & $12.33 \%$ & 7.05 & 1.08 & 7.05 & 1.08 \\
Buyer dominance & 143 & $47.67 \%$ & 5.79 & 1.64 & 8.25 & 1.58 \\
Total & 300 & $100.00 \%$ & 7.00 & 1.47 & 6.99 & 1.41 \\
\hline
\end{tabular}

Note. Source: The author.

The first step is to standardize the scores for each predictor variable (BD and SD). Any participant with a standardized score on one predictor variable that is half a standard deviation above or below the standardized score on the other predictor variable is considered to have outliers. Sequentially, it is necessary to define the percentages of 'in agreement' and the percentages of outliers in any direction. Table 1 provides a sample for reporting this descriptive information based on our example. As can be seen, almost half of the sample has different BD and SD values in one direction or the other. Based on our data, we can conclude that exploring how the discrepancies between these support sources relate to commitment makes practical sense. In the RSA syntax, this analysis can be obtained in the \#Step 4 .

\section{Conduct polynomial regression}

The researcher must regress the result on the main effects of $\mathrm{X}$ and $\mathrm{Y}$, their squared terms $\left(\mathrm{X}^{2}\right.$ and $\left.\mathrm{Y}^{2}\right)$ and the interaction term $(\mathrm{XY})$. If the polynomial regression model is significant and the inclusion of the squared terms and the interaction increases $\mathrm{R}^{2}$, the next step is to examine the 
three-dimensional response surface and the tests of its shape. Instead of examining the regression coefficients, as would be done in a common regression analysis, if the $\mathrm{R}^{2}$ (variation in the result variable explained by the regression equation) is significantly different from zero (Edwards, 2002), the results of the polynomial regression are evaluated concerning four surface test values: $a_{1}, a_{2}, a_{3}$ and $a_{4}$. The $a_{5}$ was -0.06 , indicating that the similarity is positioned exactly on the LOC. The results for the sample data, obtained from \#Step 4, are shown in Table 2.

Table 2. Polynomial regression results.

\begin{tabular}{ccc}
\hline Variable & \multicolumn{2}{c}{ Buyer satisfaction } \\
\cline { 2 - 3 } & $\mathrm{b}$ & $\mathrm{Se}$ \\
\hline Constant & $6.488^{* * *}$ & 0.12 \\
Buyer dependence $(\mathrm{X})$ & $-0.078^{\dagger}$ & 0.042 \\
Supplier dependence $(\mathrm{Y})$ & $-0.298^{* * *}$ & 0.046 \\
$\mathrm{X}^{2}$ & $-0.088^{* * *}$ & 0.014 \\
$\mathrm{X}^{*} \mathrm{Y}$ & $0.162^{* * *}$ & 0.024 \\
$\mathrm{Y}^{2}$ & $-0.044^{* * *}$ & 0.017 \\
$\mathrm{R}^{2}$ & $0.273^{* * *}$ & \\
Slope symmetry line $\mathrm{a}_{1}$ & $0.221^{* * *}$ & \\
Curvature symmetry line $\mathrm{a}_{2}$ & 0.029 & \\
\hline Slope asymmetry line $\mathrm{a}_{3}$ & $-0.376^{* * *}$ & \\
Curvature asymmetry line $\mathrm{a}_{4}$ & $-0.295^{* * *}$ & \\
\hline
\end{tabular}

Note. $\dagger \mathrm{p}<0.1 ;{ }^{*} \mathrm{p}<0.05 ;{ }^{* *} \mathrm{p}<0.01{ }^{* * *} \mathrm{p}<0.001$. Source: The author.

\section{Generate the response surface}

The response surface of the example, obtained from \#Step 5 of the code provided in this tutorial, is illustrated in Figure 4. RSA automatically provides statistical tests for four coefficients $\left(a_{1}\right.$ to $\left.a_{4}\right)$. The $X$ and $Y$ axes range from negative to positive values, and the midpoint of the scale was set to zero. In this sense, while positive values represent points above the midpoint, negative values represent points below the midpoint. In turn, the $\mathrm{Z}$-axis presents the results on its measurement scale. The response surface displays the expected values for the results of all possible combinations between the two predictors. For example, it indicates the expected $\mathrm{Z}$ value when $\mathrm{X}$ and $\mathrm{Y}$ are low (front where both are -3 ) or high (back where both are +3 ), when $X$ is high while $\mathrm{Y}$ is low (right corner), when $\mathrm{Y}$ is high while $\mathrm{X}$ is low (left corner), and all other combinations between these possibilities. In Figure 4, two lines test hypotheses about predictors, LOC (in red) and LOIC (in blue). The LOC reflects the cases where the values of $\mathrm{X}$ and $\mathrm{Y}$ correspond perfectly at all levels along the scale. By using an example of similarity to those in the tutorial, this line indicates the points where both buyers and suppliers report perceptions of low dependence at one end or report high dependence at the other. In turn, LOIC represents cases where the values of $\mathrm{X}$ are perfectly opposite to $\mathrm{Y}$ or vice versa. This line displays all points where the buyer reports a high level of dependence $(+3)$ and the supplier reports it as low (-3) or vice versa.

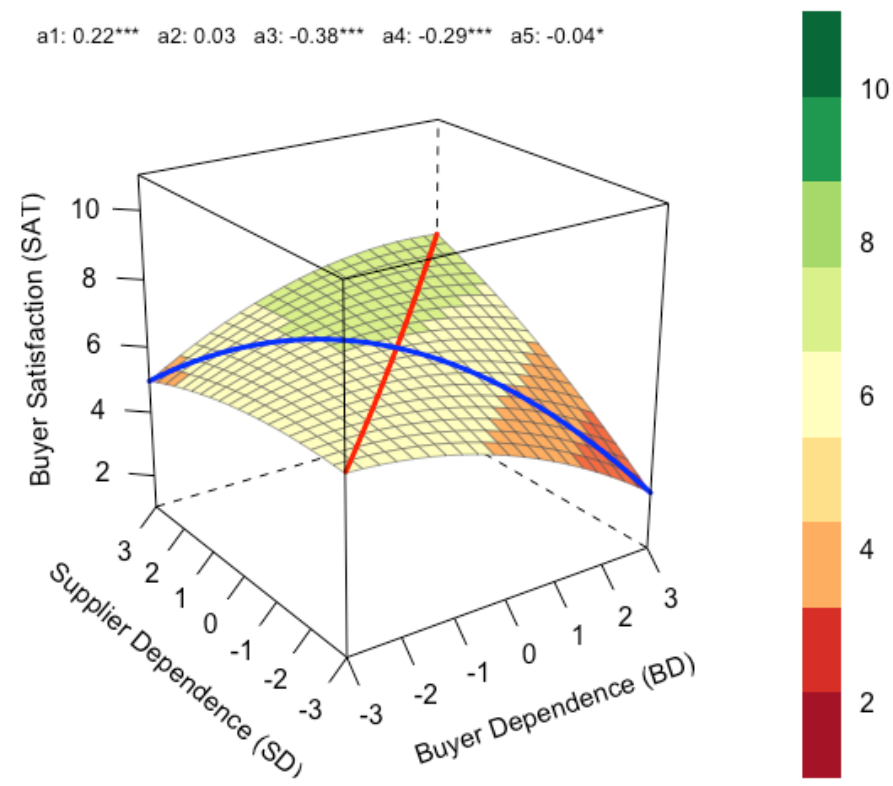

Figure 4. Response surface for our example.

Source: The author. 


\section{Interpret tests of the response surface's} shape

The next step is to interpret the RSA graph and values. It is necessary to answer three conceptual questions. First, how does the degree of congruence between BD and SD perceptions relate to SAT? Second, how does the degree of incongruence between $\mathrm{BD}$ and $\mathrm{SD}$ perceptions relate to SAT? Third, how does the direction of incongruence between $\mathrm{BD}$ and $\mathrm{SD}$ perceptions relate to SAT? The RSA package directly provides statistical tests for the four coefficients $\left(a_{1}\right.$ to $\left.a_{4}\right)$ that answer essential questions. Instead of discussing the coefficients in numerical order, the explanations will follow the conceptual questions that they test. Each of the coefficients alone is discussed separately, describing how the coefficient should be interpreted when it is significant, while all other coefficients are not.

First, RSA makes it possible to examine how the degree of congruence in the perception of the dependence of partners in the dyad is related to SAT. If there is a linear relationship across the LOC concerning SAT, $a_{1}$ will be significant. If $\mathrm{a}_{1}$ is positive, the result variable increases as the perception of $\mathrm{BD}$ and $\mathrm{SD}$ increases. If $\mathrm{a}_{1}$ is negative, the result variable decreases as the perception of $\mathrm{BD}$ and $\mathrm{SD}$ increases. The surface tests resulted in a significant positive $a_{1}(p>0.1)$ and a non-significant $a_{2}$ (see Table 3). The result indicates that when $\mathrm{BD}$ and $\mathrm{SD}$ are congruent, SAT increases as $\mathrm{BD}$ and $\mathrm{SD}$ increase. In Figure 4, the highest SAT level (in the LOC) is at the back of the graph, where the $\mathrm{BD}$ and $\mathrm{SD}$ are high, and the lowest SAT values (in the LOC) is at the front of the graph, where the BD and SD are low.

A significant $\mathrm{a}_{2}$ coefficient indicates a curvilinear slope of the LOC, or an U-shape. More specifically, $a_{2}$ indicates whether the result increases or decreases more sharply as the predictors correspond to increasingly high and low levels. A positive $a_{2}$ indicates a convex (ascending) curve or that matches that deviate from the midpoint of the scale predict higher results than those at mid-scale levels. If a is significant and negative, it would indicate a concave surface (inverted U-shape) along the LOC, that is, the result is greater when $\mathrm{X}$ and $\mathrm{Y}$ correspond at medium levels than at extreme levels. In the example presented, a positive $\mathrm{a}_{2}$ would indicate that a higher level of satisfaction is achieved or when both partners have a low level of dependence or a high level of dependence. If $\mathrm{a}_{2}$ is significant and negative, it would indicate that the results could increase or decrease more sharply as the $\mathrm{BD}$ and SD become lower or higher from some point, suggesting that the SAT is higher when both partners have a perception of the level of average dependence in relation to the other.

Second, it is necessary to interpret how the degree of discrepancy between the $\mathrm{BD}$ and the $\mathrm{SD}$ is related to the buyer satisfaction result variable, evaluating the curvature to the LOIC $(\mathrm{X}=-\mathrm{Y})$ concerning SAT with $\mathrm{a}_{4}$. A significant negative $\mathrm{a}_{4}$ indicates a concave surface; that is, satisfaction decreases more sharply as the degree of discrepancy increases. The value of $a_{4}$ in the example was negative and significant, indicating that as the discrepancy between $\mathrm{BD}$ and SD increased, SAT decreased. Figure 4 shows the results of the degree of discrepancy. The graph shows that, on the left and right of the graph, where the $\mathrm{BD}$ and SD become increasingly discrepant, the SAT decreases. A significant positive $\mathrm{a}_{4}$ would indicate a convex surface; that is, the results would increase more sharply as the degree of discrepancy increased. The LOIC curvature test, the coefficient $\mathrm{a}_{4}$, is the critical test for determining whether the predictors' incompatibility is important in general. It indicates whether the result increases or decreases more sharply as the predictors diverge. As shown, it essentially tests whether the results are higher (or lower) in the middle of the line (where $\mathrm{X}$ and $\mathrm{Y}$ match) compared to the ends of the line (where $\mathrm{X}$ and $\mathrm{Y}$ differ the most). A positive $\mathrm{a}_{4}$ indicates a convex curve (U-shape), suggesting that the result increases more sharply as the two predictors diverge. A negative $\mathrm{a}_{4}$ indicates a concave (descending) surface, suggesting that the result decreases more sharply as the two predictors diverge.

Third, one must consider how the direction of the discrepancy is related to the result, as indicated by the slope of line $\mathrm{X}=-\mathrm{Y}$ (LOIC) concerning SAT, assessed by $\mathrm{a}_{3}$. A positive $a_{3}$ indicates that the SAT is greater when the direction of the discrepancy is such that the SD is greater than the $\mathrm{BD}$ than vice versa. This suggests that buyer satisfaction is greater when the dependence on the supplier (X) exceeds the dependence on the buyer $(\mathrm{Y})$ than when the opposite occurs. If we had a significant negative $\mathrm{a}_{3}$, this would indicate that the SAT is greater when the discrepancy is such that the $\mathrm{BD}$ is greater than the $\mathrm{SD}$ than vice versa. Figure 4 shows these results, showing that in the left corner of the graph where $\mathrm{SD}$ is high combined with low $\mathrm{BD}$, SAT is still relatively high, while in the right corner of the graph where $\mathrm{SD}$ is low combined with high $\mathrm{BD}$, the SAT is very low.

Table 3 outlines each of the four questions these coefficients answer and illustrates response surfaces for possible answers to these questions. We are describing how each coefficient should be interpreted when it is significant. 
Table 3. Four response surface analysis coefficients and the questions they answer.

\begin{tabular}{|c|c|c|c|}
\hline \multicolumn{4}{|c|}{ Line of congruence: How do matches matter? } \\
\hline \multicolumn{2}{|c|}{ Slope of the line of congruence: $a_{1}$} & \multicolumn{2}{|c|}{ Curvature of the line of congruence: $\mathrm{a}_{2}$} \\
\hline \multicolumn{2}{|c|}{$\begin{array}{c}\text { Do matches at high values have different outcomes than matches at low } \\
\text { values? }\end{array}$} & \multicolumn{2}{|c|}{$\begin{array}{c}\text { Do matches at extreme values have different outcomes than matches at less } \\
\text { extreme values? }\end{array}$} \\
\hline Positive $\mathrm{a}_{1}$ & Negative $a_{1}$ & Positive $\mathrm{a}_{2}$ & Negative $\mathrm{a}_{2}$ \\
\hline $\begin{array}{c}\text { The outcome is higher when } \mathrm{X} \text { and } \\
\mathrm{Y} \text { match at higher levels than at } \\
\text { lower levels }\end{array}$ & $\begin{array}{c}\text { The outcome is higher when } \mathrm{X} \\
\text { and Y match at lower levels than at } \\
\text { higher levels }\end{array}$ & $\begin{array}{l}\text { The outcome is higher when } \mathrm{X} \text { and } \\
\mathrm{Y} \text { match at more extreme levels than } \\
\text { at midrange levels }\end{array}$ & $\begin{array}{l}\text { The outcome is higher when } \mathrm{X} \text { and } \\
\mathrm{Y} \text { match at midrange levels than at } \\
\text { more extreme levels }\end{array}$ \\
\hline \multicolumn{4}{|c|}{ Line of incongruence: How do mismatches matter? } \\
\hline \multicolumn{2}{|c|}{ Slope along the line of incongruence: $a_{3}$} & \multicolumn{2}{|c|}{ Curvature of the line of incongruence: $\mathrm{a}_{4}$} \\
\hline \multicolumn{2}{|c|}{ Is one mismatch $(\mathrm{X}>\mathrm{Y})$ better or worse than the other $(\mathrm{X}<\mathrm{Y})$ ? } & \multicolumn{2}{|c|}{ Are matches better or worse than mismatches? } \\
\hline Positive $\mathrm{a}_{3}$ & Negative $a_{3}$ & Positive $\mathrm{a}_{4}$ & Negative $\mathrm{a}_{4}$ \\
\hline $\begin{array}{l}\text { The outcome is higher when } \mathrm{X} \text { is } \\
\text { higher than } \mathrm{Y} \text { than when } \mathrm{Y} \text { is higher } \\
\text { than } \mathrm{X}\end{array}$ & $\begin{array}{l}\text { The outcome is higher when } \mathrm{Y} \\
\text { is higher than } \mathrm{X} \text { than when } \mathrm{X} \text { is } \\
\text { higher than } \mathrm{Y}\end{array}$ & $\begin{array}{l}\text { The outcome is higher the more } \mathrm{X} \\
\text { and Y deviate from one another }\end{array}$ & $\begin{array}{l}\text { The outcome is higher the more } \mathrm{X} \\
\text { and } \mathrm{Y} \text { match one another }\end{array}$ \\
\hline
\end{tabular}

Note. Coefficients are based on polynomial regression's unstandardized coefficients: $a_{1}=b_{1}+b_{2} ; a_{2}=b_{3}+b_{4}+b_{5} ; a_{3}=b_{1}-b_{2} ; a_{4}=b_{3}-b_{4}+b_{5}$. Source: Adapted from Barranti, Carlson, and Côté (2017).

Finally, our example, $a_{5}$ indicates that ridge line of the surface is positioned exactly on the LOC. This property is reflected in an additional condition $\mathrm{a}_{5}=\mathrm{b}_{3}-\mathrm{b}_{5}=0$.

\section{ADVANTAGES AND LIMITATIONS OF RSA}

The response surface analysis (RSA) procedure offers several advantages over the use of difference scores (Edwards, 2002; Humberg et al., 2019; Shanock et al., 2010). First, RSA and polynomial regression bypass the reduced reliability problems created when component measurements are subtracted from each other. Second, while the difference scores confuse the effects of its components, response surface analysis allows for a comprehensive assessment of the components' separate and joint effects. Third, when using component measures in their original form, RSA avoids ambiguities when component measures are reduced to a single score. Fourth, RSA offers tests of restrictions imposed by difference scores, treating these restrictions as hypotheses about the combined effects of the components on the result. Finally, RSA preserves the inherent three-dimensional relationship between components and the result, allowing researchers to develop and test more comprehensive and complex congruence hypotheses than the simplified models implicit in the difference scores. The empirical illustration of the RSA procedure demonstrated its advantages over the difference scores in different studies (Barranti et al., 2017; Kim \& Hsieh, 2003).

Despite its advantages, RSA and polynomial regression analysis have some limitations that provide avenues for further methodological development (Edwards, 2002). First, it adopts the standard regression premise that independent variables are measured without error. As the reliability of the component measurement decreases, the coefficient estimates can be skewed up or down. This problem can be particularly pronounced for higher-order terms used in quadratic equations. However, modest amounts of measurement error can affect constraint testing and response surface features. Second, to examine the effects of congruence in multiple dimensions simultaneously, polynomial regression equations require a large number of terms. Third, RSA applies only to congruence as a predictor. When congruence is a result, different analytical procedures are needed. Finally, although RSA can be applied to change scores as independent variables, it does not apply to change scores as dependent variables.

\section{CONCLUSION AND IMPLICATIONS}

The purpose of this tutorial article is to help researchers use, objectively, the response surface analysis (RSA) method. In addition to this specific application, the RSA methodology can address a range of other issues and challenges in the most diverse areas of study. The foundations described can be used to test the (in)congruence hypothesis and to interpret main effects or to test hypotheses that go beyond the (in)congruence effects (Edwards, 2002; Shanock et al., 2010). In supply chain studies, some questions go through whether and when (in)congruence impacts an outcome. Although relatively unknown in the purchasing and supply management literature, this analysis technique is 
growing in popularity in a variety of fields, such as Marketing (Kim, 2003; Zhang, Zhuang, Yang, \& Zhang, 2017), Innovation (Lee, Woo, \& Joshi, 2017), Organizational Behavior (Caniëls \& Veld, 2019), and Information Systems (Venkatesh \& Goyal, 2010). Caniëls et al. (2018) provide an excellent resource for understanding an application of RSA methodology. The proposal here, therefore, was to present a flexible and statistically rigorous tool, capable of advancing unresolved questions about perceptions of (dis)similarity, especially in light of the statistical challenges of such issues. The commonly used approaches distort effects or lead to incorrect inferences due to severe problems of statistical validity (Barranti et al., 2017; Edwards, 2002). By masking

\section{REFERENCES}

Barranti, M., Carlson, E. N., \& Côté, S. (2017). How to test questions about similarity in personality and social psychology research: Description and empirical demonstration of response surface analysis. Social Psychological and Personality Science, 8(4), 465-475. https://doi.org/10.1177/1948550617698204

Blau, P. M. (1964). Exchange and power in social life. New York, NY: John Wiley.

Brito, R. P., \& Miguel, P. L. S. (2017). Power, governance, and value in collaboration: Differences between buyer and supplier perspectives. Journal of Supply Chain Management, 53(2), 61-87. https://doi.org/10.1111/jscm.12134

Caniëls, M. C. J., \& Veld, M. (2019). Employee ambidexterity, high performance work systems and innovative work behaviour: How much balance do we need? International Journal of Human Resource Management, 30(4), 565-585. https://doi.org/10.1080/09585192.2016.1216881

Caniëls, M. C. J., Vos, F. G. S., Schiele, H., \& Pulles, N. J. (2018). The effects of balanced and asymmetric dependence on supplier satisfaction: Identifying positive effects of dependency. Journal of Purchasing and Supply Management, 24(4), 343-351. https://doi.org/10.1016/j.pursup.2017.11.003

Casciaro, T., \& Piskorski, M. J. (2005). Power imbalance, mutual dependence, and constraint absorption: A closer look at resource dependence theory. Administrative Science Quarterly, 50(2), 167-199. https://doi.org/10.2189/asqu.2005.50.2.167

Crook, T. R., Craighead, C. W., \& Autry, C. W. (2017). Hold back or held back? The roles of constraint mitigation and exchange diffusion on power "nonuse" in buyer-supplier exchanges. Journal of Supply Chain Management, 53(2), 10-21. https://doi.org/10.1111/jscm. 12135 or distorting results, such approaches end up undermining the validity of inferences, which have serious theoretical and practical consequences (Edwards, 2002; Shanock et al., 2010). The current demonstration is expected to provide the necessary subsidies for researchers to apply this tool in their studies and research field.

\section{NOTE}

1. $\mathrm{X}=$ female predictor variable, $\mathrm{Y}=$ male predictor variable, $Z_{-} f=$ female outcome variable have been renamed in this tutorial $Y=$ supplier dependence predictor variable, $\mathrm{X}=$ buyer dependence predictor variable, $\mathrm{Z} \_\mathrm{b}=$ buyer satisfaction outcome variable.

Edwards, J. R. (2002). Alternatives to difference scores: Polynomial regression analysis and response surface methodology. In F. Drasgow \& N. Schmitt (Eds.), Measuring and analyzing behavior in organizations: Advances in measurement and data analysis. Hoboken, NJ: Pfeiffer.

Edwards, J. R., \& Parry, M. E. (1993). On the use of polynomial regression equations as an alternative to difference scores in organizational research. Academy of Management Journal, 36(6). https://doi.org/10.5465/256822

Emerson, R. M. (1976). Social exchange theory. Annual Review of Sociology, 2(1), 335-362. https://doi.org/10.1146/annurev.so.02.080176.002003

Gaski, J. F. (1984). The theory of power and conflict in channels of distribution. Journal of Marketing, 48(3), 9-29. https://doi.org/10.1177/002224298404800303

Griffith, D. A., Hoppner, J. J., Lee, H. S., \& Schoenherr, T. (2017). The influence of the structure of interdependence on the response to inequity in buyer-supplier relationships. Journal of Marketing Research, 54(1), 124-137. https://doi.org/10.1509/jmr.13.0319

Gulati, R., \& Sytch, M. (2007). Dependence asymmetry and joint dependence in interorganizational relationships: Effects of embeddedness on a manufacturer's performance in procurementrelationships.AdministrativeScienceQuarterly, 52(1), 32-69. https://doi.org/10.2189/asqu.52.1.32

Hair, J. F., Black, W. C., Babin, B. J., \& Anderson, R. E. (2014). Multivariate data analysis. Upper Saddle River: Pearson Education. 
Hofer, A. R. (2015). Are we in this together? The Dynamics and performance implications of dependence asymmetry and joint dependence in logistics outsourcing relationships. Transportation Journal, 54(4), 438-472. https://doi.org/10.5325/transportationj.54.4.0438

Humberg, S., Nestler, S., \& Back, M. D. (2019). Response surface analysis in personality and social psychology: Checklist and clarifications for the case of congruence hypotheses. Social Psychological and Personality Science, 10(3), 409419. https://doi.org/10.1177/1948550618757600

Ireland, R. D., \& Webb, J. W. (2007). A multi-theoretic perspective on trust and power in strategic supply chains. Journal of Operations Management, 25(2), 482-497. https://doi.org/10.1016/j.jom.2006.05.004

Hoppner, J., Griffith, D., \& Yeo, C. (2014). The intertwined relationships of power, justice and dependence. European Journal of Marketing, 48(9/10), 1690-1708. https://doi.org/10.1108/EJM-03-2013-0147

Kim, S. K. (2003). A cross-national study of interdependence structure and distributor attitudes: The moderating effect of group orientation. International Journal of Research in Marketing, 20(2), 193-214. https://doi.org/10.1016/S0167-8116(03)00018-1

Kim, S. K., \& Hsieh, P.-H. (2003). Interdependence and its consequences in distributor-supplier relationships: A distributor perspective through response surface approach. Journal of Marketing Research, 40(1), 101-112. https://doi.org/10.1509/jmkr.40.1.101.19130

Kumar, N., Scheer, L. K., \& Steenkamp, J.-B. E. M. (1995). The effects of perceived interdependence on dealer attitudes. Journal of Marketing Research, 32(3), 348-356. https://doi.org/10.2307/3151986

Kumar, N., Scheer, L. K., \& Steenkamp, J.-B. E. M. (1998). Interdependence, punitive capability, and the reciprocation of punitive actions in channel relationships. Journal of Marketing Research, 35(2), 225-235. https://doi.org/10.1177/002224379803500208

Lee, K., Woo, H.-G., \& Joshi, K. (2017). Pro-innovation culture, ambidexterity and new product development performance: Polynomial regression and response surface analysis. European Management Journal, 35(2), 249-260. https://doi.org/10.1016/j.emj.2016.05.002
Leonidou, L. C., Talias, M. A., \& Leonidou, C. N. (2008). Exercised power as a driver of trust and commitment in cross-border industrial buyer-seller relationships. Industrial Marketing Management, 37(1), 92-103. https://doi.org/10.1016/j.indmarman.2007.08.006

Nyaga, G. N., Lynch, D. F., Marshall, D., \& Ambrose, E. (2013). Power asymmetry, adaptation and collaboration in dyadic relationships involving a powerful partner. Journal of Supply Chain Management, 49(3), 42-65. https://doi.org/10.1111/jscm.12011

Pfeffer, J., \& Salancik, G. (1978). The external control oforganizations: A resource dependence perspective. New York: Harper \& Row.

Reimann, F., \& Ketchen, D. J. (2017). Power in supply chain management. Journal of Supply Chain Management, 53(2), 3-9. https://doi.org/10.1111/jscm.12140

Reimann, F., Shen, P., \& Kaufmann, L. (2017). Multimarket contact and the use of power in buyer-supplier relationships. Journal of Business Logistics, 38(1), 18-34. https://doi.org/10.1111/jbl.12155

Schönbrodt, F. D., \& Humberg, S. (2020). An R package for response surface analysis (version 0.10.0). Retrieved from https://cran.r-project.org/package=RSA

Schönbrodt, F. D., Humberg, S., \& Nestler, S. (2018). Testing similarity effects with dyadic response surface analysis. European Journal of Personality, 32(6), 627-641. https://doi.org/10.1002/per.2169

Shanock, L. R., Baran, B. E., Gentry, W. A., Pattison, S. C., \& Heggestad, E. D. (2010). Polynomial regression with response surface analysis: A powerful approach for examining moderation and overcoming limitations of difference scores. Journal of Business and Psychology, 25(4), 543-554. https://doi.org/10.1007/s10869-010-9183-4

Tabachnick, B. G., \& Fidell, L. S. (2012). Using multivariate statistics (6th ed.). Upper Saddle River: Prentice Hall.

Venkatesh, V., \& Goyal, S. (2010). Expectation disconfirmation and technology adoption: Polynomial modeling and response surface analysis. MIS Quarterly, 34(2), 281-303. https://doi.org/10.2307/20721428

Zhang, C., Zhuang, G., Yang, Z., \& Zhang, Y. (2017). Brand loyalty versus store loyalty: Consumers' role in determining dependence structure of supplier-retailer dyads. Journal of Business-to-Business Marketing, 24(2), 139-160. https://doi.org/10.1080/1051712X.2017.1314127 


\section{Authorship}

\section{Antonio Carlos Rodrigues*}

Universidade Federal de Juiz de Fora, Instituto de Ciências Sociais Aplicadas, Departamento de Administração

Av. Dr. Raimundo Monteiros Rezende, no 330, Centro, 35010-

177, Governador Valadares, MG, Brazil.

E-mail address: antonio.rodrigues@facc.uff.br

(1) https://orcid.org/0000-0003-2308-4625

* Corresponding Author

\section{Funding}

The authors reported that there is no financial support for the research in this article.

\section{Copyrights}

RAC owns the copyright to this content.

\section{Conflict of Interests}

The authors have stated that there is no conflict of interest.

\section{Plagiarism Check}

The RAC maintains the practice of submitting all documents approved for publication to the plagiarism check, using specific tools, e.g.: iThenticate.

\section{Authors' Contributions}

$1^{\text {st }}$ author: conceptualization (lead); software (lead); data curation (lead); formal analysis (lead); validation (lead); visualization (lead); writing-original draft (lead); writingreview \& editing (lead).

\section{Peer Review Method}

This content was evaluated using the double-blind peer review process. The disclosure of the reviewers' information on the first page, as well as the Peer Review Report, is made only after concluding the evaluation process, and with the voluntary consent of the respective reviewers and authors.

\section{Data Availability}

All data and materials have been made publicly available through the Harvard Dataverse platform and can be accessed at:

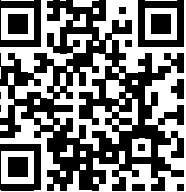

Antonio Carlos Rodrigues, 2021, "Replication Data for: "Response Surface Analysis: A Tutorial for Examining Linear and Curvilinear Effects "", Harvard Dataverse, V1. https://doi.org/10.7910/DVN/GFA5XD

RAC encourages data sharing but, in compliance with ethical principles, it does not demand the disclosure of any means of identifying research subjects, preserving the privacy of research subjects. The practice of open data is to enable the reproducibility of results, and to ensure the unrestricted transparency of the results of the published research, without requiring the identity of research subjects. 